\begin{tabular}{l} 
RCCS \\
\hline Annual Review
\end{tabular}

\section{RCCS Annual Review}

A selection from the Portuguese journal Revista Crítica de Ciências Sociais

$1 \mid 2009$

Issue no. 1

\title{
Changing Self-Medication Practices, Lay Knowledge and Rationales
}

\section{Noémia Mendes Lopes}

Translator. Sheena Caldwell

\section{(2) OpenEdition}

\section{Journals}

Electronic version

URL: http://journals.openedition.org/rccsar/143

DOI: $10.4000 /$ rccsar. 143

ISSN: 1647-3175

Publisher

Centro de Estudos Sociais da Universidade de Coimbra

\section{ELECTRONIC REFERENCE}

Noémia Mendes Lopes, « Changing Self-Medication Practices, Lay Knowledge and Rationales ", RCCS Annual Review [Online], 1 | 2009, Online since 01 September 2009, connection on 19 April 2019. URL : http://journals.openedition.org/rccsar/143 ; DOI : $10.4000 /$ rccsar. 143 


\section{Noémia Mendes Lopes}

Institute of Health Sciences Egas Moniz

Centre for Research and Studies in Sociology, Portugal

\section{Changing Self-Medication Practices, Lay Knowledge and Rationales ${ }^{*}$}

This text analyses lay knowledge and rationales in which self-medication practices are involved. After a brief critical review of the main theoretical landmarks in the analysis of lay knowledge compared with expert knowledge, the objective is to demonstrate the current forms of lay appropriation and reconversion of expert knowledge and the modes of expertisation that this shared knowledge reveals. The text discusses, on the one hand, the new forms of lay dependence on expert knowledge and, on the other, the sociological potential which these forms entail in terms of the development of new areas of lay autonomy, by focusing on the topic of selfmedication and a typology of modes of lay cognitive construction, namely spontaneous knowledge, mediated knowledge and confirmed knowledge. The constructed nature of this knowledge, which is not simply mimetically reproduced from expert sources, reveals the need for a new epistemological dialogue between the different theoretical trends that explore the reflexivity of modern societies.

Keywords: Self-medication; types of lay knowledge; lay expertisation; modern reflexivity.

\section{Introduction}

In the current phase of modernity, new forms of lay protagonism are emerging within the field of healthcare which, in turn, indicate that a new sociological matrix is being designed with regard to lay forms of knowledge and rationales for therapy management.

This introductory statement is based on the view that the traditional dichotomy between lay and expert rationales - on the basis of which interpretations of each of these spheres have been constituted - needs to be questioned in the light of the new analytical tools resulting from sociological theories of modernity and modern reflexivity.

Within the field of healthcare, as in other social fields, lay reference systems are becoming increasingly evident as open systems, permeable to the assimilation of logics and concepts produced within expert spheres. One might even say that this permeability to expert logics has become one of the principal modern means of legitimating and socially validating expert systems of action. In the field of therapy, this is immediately evident in the rising demand for, and consumption of, medical solutions for an increasingly wide range of aspects of human life traditionally managed outside the sphere of medical intervention.

Indeed, whether in the field of healthcare or in any other social field, this expansion of expertise within everyday life cannot be explained merely as an effect of the development of

\footnotetext{
${ }^{*}$ Article published in RCCS 78 (October 2007).
} 
science and technology, or simply as the consequence of any technical and ideological hegemony. In addition to the social weight of these factors, it is also the product of the actual mediation of the lay population in the social dissemination of expert logics, evident in a general cultural adherence to the consumption of solutions made available through expert systems.

Although such cultural adherence is an indisputable fact of modernity, this does not mean that we are witnessing the withering away or simple satellitisation of the specific rationality systems of lay universes. That is to say, it does not mean that these universes are being configured as mere passive recipients, or simple hostages to the forms of rationality and cognitive authority produced by expert bodies. On the contrary, the new forms of lay dependence on expertise contain conditions which favour new modes of autonomy and lay protagonism. It should be emphasized that both autonomy and protagonism have always been intrinsic to the logic underlying the formation of lay knowledge and rationales. What appears to be different nowadays are the references that are mobilised to construct these forms of knowledge and rationales.

One type of lay practice within healthcare whose analysis is particularly appropriate to the set of premises presented here is the case of self-medication. This is the domain par excellence in which to capture the diversity of referential sources that shape lay knowledge and rationales and to understand the contingency and contextual plurality of the specific configurations which these forms of knowledge and rationales entail.

This analytical exercise is based on research carried out into self-medication practices. The empirical universe included a total of 309 individuals living in the Lisbon metropolitan area, equally distributed by sex, aged between 18 and 64, and separated into 3 subgroups, one containing participants who did not suffer from any chronic illnesses and two others consisting of participants with diabetes and hypertension, respectively. ${ }^{1}$ Information was initially collected by means of a survey which involved administering a questionnaire to all

\footnotetext{
${ }^{1}$ The aim of including individuals with different health trajectories (with and without chronic illnesses) was to ensure a diverse sample with regard to their differing frequency of contact with the medical system and, specifically, with medicines. The participants with chronic illnesses were contacted through two health establishments which specialise in both types of illnesses, and the other participants were contacted in their workplace, an industrial company.
} 
individuals, followed by a second phase of in-depth interviews administered to 50 of the individuals previously interviewed. ${ }^{2}$

However, prior to this analytical incursion and in order to clarify the theoretical framework of its problematic, we begin with a brief critical reflection on the models of analysis that have influenced sociological theory on lay knowledge in healthcare.

\section{Theoretical landmarks in the analysis of lay knowledge in healthcare: A critical review}

The starting point for sociological production on lay knowledge in healthcare dates back to the early 1970s and is represented by the first studies published by Freidson $(1970,1984)$, which have become standard reference works for the sociology of healthcare. Freidson was the first author to confer theoretical visibility on the autonomy of the lay healthcare universe within the framework of modern societies. One of his conceptual findings in this area was based on the formulation of the notion of the lay referral system, establishing it as a new analytical category. The analytical and operational purpose behind this was to demonstrate that the reference matrix for lay concepts and perceptions of healthcare consisted of shared representations and experiences within the socio-cultural context of everyday experiences, rather than experiences resulting from contact with professionals. The primary importance of this new conceptual tool was that it led to a break with the Parsonian concepts that had predominated until them - i.e. formulations inspired by Parsons's model (1966) of the passive role of the patient - which circumscribed the reference structure of the lay universes within their relationship to professionals and their subordination to technical and social authority. In other words, there was no true recognition of the logic intrinsic to lay universes, which were considered merely passive receptacles for expert decisions. Any deviation from this passive receptivity fell into the category of socially deviant and irrational behaviour.

It was precisely as a result of this new theoretical concept introduced by Freidson and the recognition of the specific identity of lay universes that a series of other work on lay representations and practices in healthcare began to develop. Their merit was, unarguably, the contribution they made towards establishing a new understanding of the lay spheres of

\footnotetext{
${ }^{2}$ For more detailed information on the methodology for the research in question, see Lopes (2001, 2003). The research was carried out through CIES/ISCTE and was funded by INFARMED (National Institute for Medicines and Health Products) and the FCT (Foundation for Science and Technology) - (POCTI/SOC/36479/99).
} 
healthcare and their endogenous rationales. However, some results of this new approach also helped foster - even contrary to their actual analytical intentions - a certain aura of exoticism for lay universes. Indeed, the intention to establish a firm dividing line between lay and expert universes and to describe the separate nature of the forms of cognition which organise each of them, ended up by circumscribing forms of lay knowledge within the category of beliefs or knowledge rooted in tradition, without recognising their status as knowledge. This is actually a conceptual view that still has its supporters today, not only in sociology but also in other branches of the social sciences, in which lay knowledge of healthcare continues to figure as a kind of exotic cultural item sometimes presented as something that should be preserved and at other times as the expression of idiosyncrasies and irrationalities that impede longed-for advances in healthcare.

On a somewhat different note, another thread of analysis has developed parallel to this which, unlike the previous perspective, is directed primarily towards a relational reading of expert and lay universes (Navarro, 1976; Hart, 1985). This has involved bringing to light the power relations which structure interactions between the lay and expert universes. This therefore made it possible to recognise the subordinate relationship - as well as the mechanisms supporting it - within which the forms of lay protagonism are inscribed in the overall framework of professional dominance. Although this focus has the merit of making the issue of power visible - making it an analytical category indispensable to deciphering the hierarchical forms of coexistence between separate rationales and forms of knowledge - it has, on the other hand, taken away the visibility of the forms of lay autonomy that exist even within the hegemony of an expert rationale.

These conceptual formulations began to be questioned at the end of the 1980s with the emergence of theoretical approaches to modernity and their contribution towards a new interpretation of the relationships between lay and expert universes. Within the framework of these new contributions, three theoretical-analytical categories should be highlighted, given that they have proved decisive to the new lines of inquiry which, from this time onwards, began to develop in connection with lay rationales and knowledge.

One of these categories concerns the conceptual structure that encapsulates the notion of the dissemination of expert systems within everyday life (Giddens, 1992; Beck, 1992). This gave visibility to the intensifying relationships between the lay population and experts, enabling new forms of social proximity between both universes to be understood. 
Another of the categories refers to the concept of reflexivity (Giddens, 1992). This concerns a concept which substantiates and confers visibility on the increasing centrality which the diffusion of expert information assumes in the constitution of social practices.

The third category refers to the questioning of the notion of science itself as homogenous knowledge (Santos, 1989, 2000; Giddens, 1992; Nunes, 2001). This leads to the emergence of new frameworks of uncertainty, as well as to the ambivalent relationship between trust and scepticism which characterises the relations of lay people with expert information.

It was through this new conceptual configuration that lay forms of knowledge and rationales on healthcare began to be considered. However, two theoretical trends which pursue different perspectives can be distinguished.

One trend focuses on the dependence of lay knowledge on expert knowledge - due to the dissemination of expert systems in everyday life - and accounts for the gradual draining away of the autonomy of lay knowledge as a result of the increasing colonisation of everyday lay experience by the hegemony of expert knowledge (Peterson, 1997; Santos, 2000). ${ }^{3}$

The other trend indicates the increasing autonomisation of lay universes. The search for alternative solutions to expert solutions, specifically within the field of healthcare, is presented as empirical evidence of the new forms of autonomy. Scepticism of science and increasing lay reflexiveness provide the basis for this new social framework (Williams and Popay, 1994; Sharma, 1996; Williams and Calnan, 1996).

Either of these interpretations - the gradual expert colonisation of lay universes or the new forms of autonomisation of the latter - still remains a necessary exercise in order to account for an increasingly complex reality in which dependence and autonomy no longer constitute opposite poles but (paradoxically) reveal themselves to be increasingly interdependent realities. However, each of these perspectives is limited by their analytical closure. Both focus on only one aspect of the social dynamic that currently permeates the relationships between expert systems and lay universes.

The need therefore arises for a different kind of dialogue between these theoretical approaches. My aim is to put this into practice by presenting an analytical exercise on self-

\footnotetext{
${ }^{3}$ The emphasis on the effect of "colonisation" does not exclude other contributions within this theoretical trend relating to the emergence of new signs of the emancipation of lay knowledge. However, in revealing the hegemonic relationship that expert systems establish with lay universes, this emphasis represents the analytical advantage of this trend in terms of the current debate on rupture and continuity between the two paradigms of knowledge.
} 
medication and the modes of constructing the forms of knowledge and rationales on which lay practices are based.

\section{Self-medication practices and their sociological reframing}

The recurrence of contacts between the lay populace and expert systems and agents which characterises the current phase of modernity ${ }^{4}$ - and the way in which the latter increasingly mould everyday experiences point, in fact, to a process whereby experts increasingly colonise lay universes. The way in which self-medication ${ }^{5}$ practices are configured nowadays is, in itself, illustrative of this colonisation or, to put it in different terms, the increasing lay dependence on expertise.

In effect, recourse to self-medication began to increase as the phenomenon of medicalisation was disseminated throughout society, i.e. to the extent that the social fabric became impregnated with medical concepts of health and illness as a consequence of people's increased contact with expert healthcare agents. ${ }^{6}$ In this way, lay familiarity with medicines increased, due primarily to the fact that they were the main means of managing the treatment prescribed by medical decisions. Therefore, as the consumption of medical care increased, there was a parallel increase in the prescription and consumption of these therapeutic resources. Medicines gradually ceased to figure in the cultural mind as a "rare and esoteric commodity," and became a "common and exoteric commodity" (Van der Geest and White, 1989). The phenomenon of medicalisation thereby gave rise to another related phenomenon, that of the pharmacologisation of everyday life, ${ }^{7}$ which involves the increased recourse to self-medication witnessed in recent decades. ${ }^{8}$

\footnotetext{
${ }^{4}$ Depending on the theoretical current in question, this phase of modernity has been called post-modernity, late modernity or reflexive modernity

${ }^{5}$ The notion of self-medication is used in this text in its generally accepted meaning, i.e. the use of medicines without prior medical guidance. On the problematic of the ideological content that this notion encapsulates, specifically with regard to the normative and ethical-professional codes that underlie it, see Lopes, 2003: 26-40.

${ }^{6}$ For a more detailed explanation of the concept of medicalisation and the phenomenon it refers to, see Crawford, 1980; Williams and Calnan, 1996.

${ }^{7}$ For a more detailed explanation of the concept of pharmacologisation and the phenomenon it refers to, see Lopes, 2003: 47-54.

8 In European societies, the growing use of self-medication began to reveal itself from the 1970s onwards (WHO, 1988; Richard and Senon, 1996). In the specific case of Portugal, despite the incipient and disjointed nature of official data on this subject, it can be affirmed that this increase became more significant from the 1980 s onwards, with the creation of the category of over-the-counter-remedies and the fact that almost all of these ceased to be subsidised by the state. On the specific case of Portugal, see Lopes, 2003: 7-20.
} 
In addition, most of the available records indicate that the great majority of selfmedication practices apply to health problems traditionally managed by recourse to domestic knowledge, which includes the so-called home remedies (Quaeyhaegens, 1996). This was equally evident in the research data which provides the empirical support for this article, given that approximately $80 \%$ of the health problems that had led to the use of selfmedication were related to general complaints such as headaches, flu, digestive problems, etc. (Lopes, 2001). It therefore focussed on symptoms that were rarely managed traditionally by recourse to pharmaceutical drugs. Moreover, in interviews with members of the older generation during the research, there was frequent mention of the fact that nowadays they took medicine to treat "ailments" (sic) that could easily be treated in another way and which, when they were children or youngsters, were treated without medicine, whereas now this form of treatment had become a more practical solution.

What this new framework shows is that current self-medication practices reflect the gradual expropriation of traditional cognitive resources and lay autonomy in the everyday management of treatment. In fact, medicines are therapeutic items over whose (complex) production processes the lay universe has no cognitive control - their virtual control over use is dissociated from any control over production - unlike the therapeutic resources produced within the home, in which control over use and production remained inseparable. In this sense, self-medication is clearly a practice that expresses a growing lay dependence on expert systems.

However, this aspect of dependence assumes other forms if we note that the majority of self-medication practices involve medicines that have previously been prescribed by a doctor. In other words, the initial introduction to the medicine is generally through a doctor - or another expert agent - and it is only later that they are used on the initiative of the lay populace. In the research study in question, $63.8 \%$ of the medicines used (on the last occasion the interviewees used self-medication) had been prescribed by a doctor or recommended by a chemist on another occasion, and only the remaining $36.2 \%$ were used without any previous expert intervention (Lopes, 2001). Given that over a third of the latter category had been recommended "by someone known," and that therefore previous expert intervention had also been involved in accessing these therapeutic resources, the percentage of forms of self-medication involving recourse to medicines obtained through the intervention of experts is even more accentuated. It is therefore a matter of practices 
which typify a gradual lay appropriation of expert logic for the management of treatment, and it is this appropriation that paves the way for new forms of lay autonomy in everyday healthcare.

However, from an initial reading it might be said that these appropriations are nothing but an exact imitation of expert opinions, which would thus eliminate from the outset any analytical possibility of referring to a new lay protagonism, or even a new matrix for lay knowledge. But the lay appropriations of expert logic which are found in self-medication practices are not the only support for such lay initiatives in the management of treatment. There is always practical lay control (Baszanger, 1998) over the validity of these approaches, and even over the validity of expert decisions. This control is manifest in the central position assumed by bodily responses in lay criteria for validating treatment strategies.

In fact, bodily responses constitute the main means of practical control over the effectiveness of the medicines used. Medicine used for self-medication is, in general, something that has already proved to produce the desired results, whether though the direct experience of the user or through experiences shared by other users. It is this same criterion of bodily response that legitimates lay decisions to continue or suspend treatments, even when taken under direct medical prescription. The following excerpts from interviews illustrate the central importance conferred on bodily responses:

... when I get a cold or a fever I always take Nimed... [Q: Why?]. Why? First because it always works, I've used it for years and it always has good results, and also because I don't feel like it's doing me any harm in any other way, I don't get any side effects ... (woman, aged 22, college student [3rd year], diabetic, interview 11)

... I suffer from osteoporosis and it always hurts me here ... and it's hard for me to use my left arm. I started taking some pills the doctor prescribed for me, I don't remember the name because it was more than a year ago and I only took them for a short time. They made my stomach bad, gave me heartburn and gave me a pain here ... So I stopped taking them and never went back to the doctor. I started using an ointment again, Reumon-gel, which I'd used before, and it always makes me feel better. But one day I'll have to go back to the doctor because I know that it only takes away the pain, it doesn't cure it... (man, aged $57,<9$ years of schooling, with hypertension, interview 22)

This means, therefore, that the body has a dual status within the framework of lay rationales on healthcare: it is not only the recipient of therapeutic interventions, but is also transformed into an instrument which monitors the efficiency of these interventions, whether lay or expert. Thus, it is through this central focus on bodily responses that direct 
lay control is exerted over the options assimilated through contact with expert agents. Practical experience thus constitutes a cognitive category that invalidates all interpretations that confine lay decisions to the mere imitation of expert logic.

It is through this ongoing conjunction of practical experience and information assimilated through contact with sources of expert information that lay trajectories for the management of treatment are constructed.

\section{Knowledges in process and lay expertisation}

Both direct bodily experience and the frameworks of social interaction through which this experience is validated play a central role in the production of lay reference systems for medicines. Thus, they are the two aspects that organise the overall matrix on which cognitive lay trajectories are based. It is within this matrix that the primacy of experience is constantly updated, within which the inherent practical nature of this sphere of knowledge is, in turn, inscribed (Williams and Popay, 1994).

On the basis of this matrix, the concrete modes of cognitive lay acquisition assume different configurations and follow multiple itineraries. The various processes of learning involved reveal the constructed nature of this knowledge (Baszanger, 1989, 1998) as well as the impossibility of reducing it to a mimetic assimilation of bodily responses or references circulating within the frameworks of interaction.

The learning component underlying any of the modes of generating knowledge about medicines is not an immediate and directly visible fact. Nevertheless, it can be captured analytically by using certain operational categories, such as those formulated by Nitcher and Vuckovic (1994) in their triptych of direct empirical learning, learning by example and learning through information. The use of these categories makes it possible to restore visibility not only to the constructed nature of the lay knowledge activated through the use of medicines, but also to the different types of knowledge consolidated by these forms of learning.

Direct empirical learning is involved in situations in which the use of medicines occurs in circumstances where there is uncertainty regarding the complexity of the health problem concerned. In these situations, medicines are used both as an attempt at treatment and a means of diagnosis in order to assess the perceived symptoms, and also to determine, in the light of the resulting bodily responses, whether there is a need to seek professional care. 
Here, control over the uncertain trajectory is ensured by the certainty that the appropriateness or otherwise of the solution adopted can be detected by reading the physical warnings.

Outside the direct sphere of self-medication, Conrad (1985) also refers to other lay diagnostic strategies involving the same logic of direct empirical learning. This occurs when patients decide to suspend or reduce prescribed medicines as a means of assessing the origins of side effects, which are assumed to be related to the medicines being taken, or as a means of assessing their therapeutic effectiveness in terms of the symptoms developing when treatment is interrupted or reduced (1985: 32). These strategies configure what this author terms the rational empirical method that is intrinsic to laymanship.

The results obtained from these different types of practices generate a legacy of provisional knowledge which is assumed as knowledge subject to review in the light of each new experience. However, as practices become routine over time, they become firm knowledge, which is naturalised and activated as spontaneous knowledge.

There are many examples in which the nature of these trajectories as processes can be detected, as this second interview extract illustrates:

The last time I went to the doctor's must have been over a year ago, and it was because of a serious throat infection. I started to feel pain and it hurt when I swallowed, and I was getting those white spots with pus. I started taking a syrup and some pills I had at home - I don't know what they were called, but they were a kind of anti-inflammatory pill and they usually worked well. But this time the infection was more complicated and it wasn't getting any better, so I had to go to the doctor and I even had to take penicillin... (woman, aged 19, 9 years of schooling, healthy, interview 49)

As this story illustrates, when the solution adopted does not work as a treatment strategy, the (subjectively mediated) effect is to confirm that the complexity of the problem exceeds lay competence and requires specialist intervention. However, in these circumstances, it is, once again, the medicine and the representations to which it is subjected that serve to confirm the complexity of the problem, which, in this case, was emphatically expressed by highlighting the need to "take penicillin." It is not, therefore, a case of questioning the spontaneous knowledge initially mobilised to manage the situation; on the contrary, this knowledge is revalidated given that it made it possible to differentiate limits for the complexity that legitimises lay or professional intervention. 
In other situations, direct empirical learning gives way to learning by example. This is not entirely separate from the previous mode - it is, rather, a specialised form of it - but it enables us to capture the process of constituting another type of knowledge. Whilst the logic of production is the same - since it is through successive personal or shared experiences that the knowledge activated in situations considered similar is produced - the difference is that the (subjectively mediated) guarantee of the effectiveness of the chosen medicines lies in the fact that they have been prescribed by the doctor on previous occasions and have had the desired results. As a result, they are no longer used as an attempt at therapy, but as a solution. However, the possibility of moving from attempt to solution is not ensured by medical validation of medicines alone if this is not combined with the deeper experience of recognising symptoms and responses to the chosen treatments.

Each of the following examples illustrates in detail the progression of these cognitive sequences within this mode of learning:

... in situations we've already been in two or three times before, there's always that knowledge, that experience that you acquire, isn't there? For example, when I get a cold I know from experience that if I don't take something, in two or three days' time I'll feel a lot worse, so I take a flu remedy or something like that so that it doesn't get worse. I'll give you another example: some time ago I had an infection in my finger and I took an antiinflammatory straight away but it didn't cure the problem, so I ended up having to go to the doctor, but at least it stopped it from getting too bad ... (man, aged 33, college graduate, diabetic, interview 1)

.... while ago I said I don't self-medicate, but maybe that's not completely true. For example, I know what pain from colitis is and I know I should take Pankreoflat, and if the pain is very bad I should also take a Buscopan, otherwise it won't go away. That's self-medication, but it's by using medicines prescribed by the doctor and I already know what they are for, I don't do it randomly.... (woman, aged 39, 11 years of schooling, with hypertension, interview 25)

If, in analytical terms, the difference between the construction of this kind of knowledge and spontaneous knowledge lies in the displacement of learning from the testing method (and therefore from the management of uncertainty) to a recognised diagnostic framework (and therefore to controlled uncertainty), the respective forms of knowledge that are produced must also be distinguishable from each other. On the level of the analytical study in question, these cognitive resources assume the shape of confirmed knowledge, which provides a more immediate legitimacy when they are activated than that of the previously described spontaneous knowledge. 
Given that the origins of confirmed knowledge are primarily to be found within the context of interaction with the medical system, it is usually assumed that this is a matter of knowledge resulting from direct assimilation of medical information made available to the patient during treatment. However, this information occupies only a residual space, as can be seen when the nature of the social process in which it is inscribed is analysed.

In fact, the claim to a supposed medical didactics which fosters lay modes of assimilating expert references - of which the current reconversion of traditional lay reference systems is said to be a part - is revealed to be disproportionate to its actual social expression. Rather, it is within the context of medical pragmatics, and particularly in its most standardised forms of operation, that the conditions emerge for the lay appropriation of medical knowledge.

In this context, the increasing routinization and standardisation of medical prescriptions constitute the main means of lay access to the assimilation and incorporation of expert knowledge. It is through this that a learning trajectory emerges in which each medicine or set of medicines is associated with the treatment of certain symptoms, due to the fact that they are repeatedly prescribed within the context of identical sets of symptoms. This learning trajectory cannot be reduced merely to the act of associating medicines with symptoms. The effectiveness of the medicine is always reassessed through the filter of bodily responses and, as a result, treatment options are adopted or excluded on the initiative of the lay population.

The central role which learning by empirical experience continues to play, even when the cognitive references mobilised are assimilated from expert practices, underlies the logic of a lay autonomy which prevails in the re-working and readjustment of expert references to the foundational matrix of lay knowledge.

This process of lay appropriation generated by the routinization and standardisation of prescriptions also shows that, although it is the doctor's action in writing out a prescription that gives rise to the possibility of lay access to expert knowledge, it is the medicine and its results that confer lay intelligibility on the medical act. In other words, it is the medicine which, in the social process of its lay appropriation, becomes a resource for decoding and making expert knowledge intelligible. This is the same as saying that the metonymic effect of medicines - which corresponds to representing the medicine as an extension and substitute for the doctor, in the sense that it is the distillation of the doctor's own knowledge, turned into therapeutic technology (Van der Geest and White, 1989) - may be understood in a 
broader sense. Medicines do not only represent an extension and replacement of the doctor, but are also the means of enabling the lay populace to decode and appropriate medical knowledge. ${ }^{9}$

The possibilities of cognitive appropriation which prescription medicines represent are most evident in the way they are (later) used for the purposes of self-medication. The following extracts illustrate the social processing involved in such appropriations:

... whenever I take medicine without going to the doctor it's because the first time I used it, it had been prescribed to me by the doctor. After that, there you are, since I saw that it worked, I began using it whenever I think I need it ... (man, aged 30, college graduate, diabetic, interview 3)

... for years and years I was constantly getting throat infections. When I went to the doctor he always prescribed the same medicine, essentially based on antibiotics... A lot of the time I didn't even go to the doctor... why should I?... he'd only prescribe something I already had at home... (woman, aged 45, college graduate, diabetic, interview 47)

... so I prefer to take medicine on the doctor's recommendation. But when it's things you've already had, things you know about, like a sore throat or an inflammation, you know the family doctor is going to prescribe certain medicines, don't you?... So you just go down to the chemist's and ask them for, I don't know, Brufen, something well-known... I think there's no need to go and bother the doctor when it's just a small thing ... (woman, aged 52, 9 years of schooling, with hypertension, interview 27)

I always keep any leftover medicine and as long as it's still within the sell-by date I use it again if I need to. I've done this a lot with allergies, colds or minor ailments and aches and pains because I know that if I go to the doctor he'll prescribe the same thing or something similar to what I already have at home... (woman, aged 34, college graduate, healthy, interview 43)

What also stands out in these statements is the instrumentality acquired by prescription medicines in legitimising not only practices but, at the same time, the cognitive references that preside over these practices. In fact, the reiterated affirmation that the medicines used had already been prescribed on previous occasions serves, in terms of individual

\footnotetext{
${ }^{9}$ This social use of medicines in the specialisation trajectories of lay knowledge is comparable to that of diagnostic technological resources (X-rays, clinical testing, three-dimensional imaging, etc.) and self-diagnosis (cholesterol and blood pressure testing, etc.), which are included by Vuckovic and Nichter (1997) as possible resources for the lay control of healthcare. It may be added that they also function as decoders of medical diagnostics. These resources present diagnostics in the form of images or numerical figures, which make them accessible to lay people as they become familiar with their use. Although there may remain a part of medical diagnostics which, due to its indeterminate nature, cannot be included in technological codification, this does not, at least in less complex situations, invalidate the fact that technological codification may eventually reinstate the possibilities of lay control and access to expert knowledge. In this scenario, it is the actual centrality of medical mediation in the management of healthcare, supported by the inaccessibility of medical knowledge to the lay population, that may be reconfigured as lay appropriation of medical technology expands.
} 
subjectivities and their externalisation, as support for the validation of the actual empirical experience that determined that they should continue to be used. The expert references that have been assimilated thus convert empirical experience into a cognitive resource legitimised by the actual underlying expert support.

This signifies that the routinization of people's contacts with the medical system has not only led to new possibilities for lay access to the incorporation of expert knowledge, but has also enabled its use as a tool for constructing new forms of legitimising lay knowledge. In some interviews, the search for this legitimation was expressed in particularly explicit ways:

... I've always been concerned, not only to listen carefully to what the doctor tells me, but also to ask questions, to know why something has happened, why it is that I'm taking this now and not that ... I always like to ask, even if it just means being told what I already know... (man, aged 29, 12 years of schooling, healthy, interview 36 )

Although the legitimation derived from the appropriation of expert knowledge is important to individual subjectivities, the boundaries between lay and expert legitimacy remain well-defined in terms of the forms of social recognition which circumscribe each one. Indeed, the knowledge activated in lay practices, even when it incorporates expert references, is never invoked as having the status of knowledge in its universal sense, but primarily as practical cognition used in the context of occurrences that are well controlled by familiarity. The legitimacy invoked for this cognition is restricted to the framework of lay legitimacy, without presupposing any confrontation with expert legitimacy or any claim to challenge it. This demarcation of the spheres in which each of these legitimacies is exercised therefore identifies the social conditions that make the coexistence of frameworks of lay and expert rationales intervening within the same universe compatible.

The learning by information mode is distinguished from the two previous categories by the deliberate act of combining information gathered from different sources - expert information disseminated by the mass media, the Internet or specialist magazines - to serve as the basis for weighing up the options that may be chosen. However, this form of learning also does not have an autonomous space within the construction of lay cognition that can be separated from the previous modes of learning centring on the primacy of empirical experience. Its effect is essentially to produce mediating knowledge, which does not challenge the primacy of experience or the input of spontaneous knowledge or confirmed knowledge, but rather reorganises the conditions for validating experience itself. 
Although this mode was more often detected in the treatment strategies of the better educated interviewees, this does not necessarily mean that these social groups have a specific cultural predisposition to make use of a particular type of knowledge. ${ }^{10}$ On the contrary, it is the framework of circumstances - and, in particular, the uncertainty involved in treatment strategies - that, in general, emerges as the factor favouring investment in mediating knowledge. The contingent nature of circumstances becomes evident in several narratives, especially in the case of the more educated interviewees:

... Two or three years ago I started to have problems with sleep apnea, I was waking myself up with my snoring. I began discussing this with some friends who had the same problem, and then I started to look for information about it on the Internet. With this information I at least knew that the problem could be treated and for this I had to consult a specialist. I had actually thought that it was something that couldn't be treated... (man, aged 45, college graduate, with hypertension, interview 16)

... There are those people who go to the doctor and just take whatever they are prescribed without finding out anything more about it - my in-laws are like that. Whereas my wife and I try to find out as much as we can, either on the Internet or by talking to friends, before we decide whether to follow a course of treatment, especially if its something new ... (man, aged 41 , college graduate, healthy, interview 35 )

The analytical interest in dissociating each of these modes of learning is essentially that of revealing the plurality of types of knowledge obscured within the broad category of lay knowledge, whilst also conferring visibility on the subtle social processes which determine the space assigned to each of the different types of knowledge, or to the levels at which they intersect, according to the circumstances of each action. It is at this level that the constructed nature of these forms of knowledge becomes clearly visible, given their adjustment to the personal and social circumstances of individuals, as well as their indelible link to the primacy of bodily experience and shared social experiences.

As they are constructed and not passively imitated, the different types of lay knowledge provide individuals with the possibility of direct control in applying them, and this fosters a belief in their safety when mobilised in everyday life. This belief in safety is especially clear in

\footnotetext{
${ }^{10}$ The frequent confusion between (cultural) predispositions and (cultural) resources has fuelled an ideology of established cultural profiles, particularly in the field of healthcare, which legitimises differentiated access to information. Any cultural predisposition in this or any other area can only be upheld in sociological terms as the expression/retranslation of the social conditions in which such predispositions are produced (Bourdieu, 2000, 1979). Hence, the unveiling of different types of lay knowledge and the ways in which they are activated in treatment strategies requires the exclusion of any kind of categorisation according to cultural predispositions, since these categorisations obscure the structural conditions and situational dynamics that mobilise different types of knowledge.
} 
the options for self-medication. In fact, there is a greater likelihood of doubt in relation to prescribed medicines used for the first time than in relation to medicines repeatedly used for self-medication. Whereas, in the first case, trust in the knowledge of the prescriber is activated, in the second case, trust is activated on the basis of knowledge mastered and controlled by direct experience.

It is in this dissymmetry, present not only in the distinctive nature of lay knowledge and expert knowledge but, above all, in the way in which the lay relationship to both forms of knowledge is structured - i.e. direct lay control incorporated into one and excluded from the other - that the conditions for making knowledge of self-medication autonomous are generated. It is also in terms of this endogenesis of lay control with regard to knowledge activated by the use of medicines that the parallel limited scope of institutional warnings aimed at combating the habit of self-medication may be understood.

Thus, the idea of an absence of rational thinking in self-medication options is offset by a framework of reflexiveness continually activated by recourse to different modes of learning. It is a reflexiveness that it has become even more imperative to activate in the construction of a separate lay perspective (Baszanger, 1998), as sources of information have become more contradictory, particularly specialised sources. Hence, within a context of uncertainty originating in the current increase in contradictory information, the construction of a separate lay perspective takes on the status of a social antidote that preserves the unity and integrity of cognitive referencing, functioning as a stronghold of ontological safety in the everyday management of healthcare.

It is by connecting this plurality of analytical focuses that self-medication is indisputably revealed as one of the spheres with the greatest visibility in the recomposition and specialisation of lay knowledge on healthcare. Indeed, the gradual social disqualification of traditional domestic therapeutic knowledge has given way to the gradual appropriation of new cognitive resources made available by the increasing pharmacologisation of everyday life. This means that the logic and rationales of self-medication are not only distinctive in terms of the constructed nature of the knowledge they are based on, but also in terms of the expertisation trajectories which the sphere of self-medication favours. 


\section{Concluding remarks}

The trajectories for the reconversion and expertisation of lay cognitive resources analysed above reposition the knowledge activated by self-medication practices within the framework of a lay rationale that cannot be reduced to the mere imitation of the pragmatics embodied in professional rationales. However, neither is it dissociated from, nor impermeable to, these spheres. Hence, this approach supports the idea that the plurality of the cognitive resources mobilised and activated within trajectories of reconversion and expertisation of lay knowledge on healthcare cannot be confined to the status of mere beliefs that has been ascribed to them, and far less should it continue to be seen as lacking legitimacy.

As other authors have argued (Popay and Williams, 1996), the attribution of the status of knowledge to lay cognition within the sphere of healthcare is not only based on its actual cognitive nature and effective social use, but also constitutes an imperative for reconceptualising the modes of intervention and professional repositioning regarding lay universes.

However, this imperative needs to be expanded. It cannot be restricted to recognition of the cognitive nature of lay knowledge, but also requires recognition of its plural and contingent nature. It is knowledge that is neither homogenous nor universalisable, precisely because this knowledge is constructed within the frameworks of personal contingency and socio-cultural diversity.

In the research study that served as a basis for this article, this diversity was found in the multiple combinations which, according to the contingencies of each situation and the resources of each individual, regroup the mosaic of spontaneous knowledge, confirmed knowledge and mediating knowledge activated by lay therapeutic initiatives.

The study also demonstrated that the cognitive constructions involved are based on a dual affiliation: they are not only derived from the reflexive appropriation of expert references, but also from the repeated reassessment of the efficacy of these references within the framework of practical experiences.

It is precisely the fact that they are constructed, rather than passively absorbed, that affirms the new forms of lay autonomy in relation to expert hegemony. In this sense, we may refer to newly emerging rationales, which cannot be understood outside the framework of the increasing interdependence of lay and expert universes. One of the challenges which sociology faces today is that of providing a more epistemological and dialectical 
interpretation of the actual effects of modern reflexivity, an interpretation that can account for these new interdependences.

Translated by Sheena Caldwell

Revised by Teresa Tavares

\section{References}

Baszanger, Isabelle (1989), "Douleur, travail médical et expérience de la maladie," Sciences Sociales et Santé, VII(2), 5-34.

Baszanger, Isabelle (1998), "La migraine - connaissances descriptives, traitement et prévention," Rapport établi à la demande de la Mutuelle Génerale de l'Education Nationale, INSERM, 251-263.

Beck, Ulrich (1992), Risk Society: Towards a New Modernity. London: Sage.

Bourdieu, Pierre (2000), Esquisse d'une théorie de la pratique. Paris: Seuil.

Bourdieu, Pierre (1979), La distinction: critique sociale du jugement. Paris: Les Éditions de Minuit.

Conrad, Peter (1985), "The Meaning of Medications: Another Look at Compliance," Social Science \& Medicine, 20(1), 29-37.

Crawford, R. (1980), "Healthism and the Medicalization of Everyday Life," International Journal of Health Services, 10(3), 365-388.

Freidson, Eliot (1970), "Influence du client sur l'exercice de la Médecine," in Claudine Herzlich (ed.), Médecine, maladie et société. Paris: Mouton, 225-238.

Freidson, Eliot (1984), La profession médicale. Paris: Payot.

Giddens, Anthony (1992), As consequências da modernidade. Oeiras: Celta [Portuguese translation of The Consequences of Modernity. Stanford: Stanford UP, 1990].

Hart, Nicky (1985), The Sociology of Health and Medicine. Lancashire: Causeway Books.

Lopes, Noémia (2001), "Automedicação: algumas reflexões sociológicas," Sociologia, Problemas e Práticas, 37, 141-165.

Lopes, Noémia (2003), Automedicação: práticas e racionalidades sociais. Lisbon: ISCTE (PhD dissertation).

Navarro, Vicente (1976), Medicine under Capitalism. London: Croom Helm.

Nichter, Mark; Vuckovic, Nancy (1994), “Agenda for an Anthropology of Pharmaceutical Practice," Social Sciences \& Medicine, 39(11), 1509-1525.

Nunes, João Arriscado (2001), "Teoria crítica, cultura e ciência: O(s) espaço(s) e o(s) conhecimento(s) da globalização," in Boaventura de Sousa Santos (ed.), Globalização, Fatalidade ou utopia? Porto: Afrontamento, 299-338.

Parsons, Talcott (1966), El Sistema Social. Madrid: Revista de Occidente.

Peterson, Alan (1997), "Risk, Governance and the New Public Health," in A. Peterson; R. Bunton (eds.), Foucault, Health and Medicine. London: Routledge, 189-206. 
Popay, Jennie; Williams, Gareth (1996), "Public Health Research and Lay Knowledge," Social Sciences \& Medicine, 42(5), 759-768.

Quaeyhaegens, William (1996), "Las realidades del mercado de la automedicación: hoy e mañana," Actas do Simposium La Automedicación en los Sistemas de Sanidad Europeos, Brussels, 23 de Janeiro, 23-40.

Richard, Denis; Senon, Jean-Louis (1996), Le médicament. Paris: Flammarion.

Santos, Boaventura Sousa (1989), Introdução a uma ciência pós-moderna. Porto: Afrontamento.

Santos, Boaventura Sousa (2000), A crítica da razão indolente - contra o desperdício da experiência. Porto: Afrontamento.

Sharma, Ursula (1996), "Using Complementary Therapies: A Challenge to Orthodox Medicine?," in S. Williams; M. Calnan (eds.), Modern Medicine - Lay Perspectives and Experiences. London: UCL Press, 230-255.

Van der Geest, Sjaak.; Whyte, Susan R. (1989), "The Charm of Medicines: Metaphors and Metonyms," Medical Anthropology Quarterly, 3(4), 345-367.

Vuckovic, Nancy; Nichter, Mark (1997), "Pharmaceutical Practice in the US: Research Agenda for the Next Decade," Social Science and Medicine, 4419, 1285-1302.

WHO (1988), Self-Medication in Europe. Copenhagen: Regional Office for Europe.

Williams, Gareth; Popay, Jennie (1994), "Lay Knowledge and the Privilege of Experience," in Jonathan Gabe et al. (eds.), Challenging Medicine. London: Routledge, 118-139.

Williams, Simon J.; Calnan, Michael (1996), "Modern Medicine and the Lay Populace: Theoretical Perspectives and Methodological Issues," in S. J. Williams; M. Calnan (eds.), Modern Medicine - Lay Perspectives and Experiences. London: UCL Press, 2-25. 